\title{
DOES INTERFERON (IFN)S EXIST IN CRUSTACEA?
}

\author{
Dewi Syahidah"*\# and Leigh Owens ${ }^{* * *}$ \\ ") Research Institute for Mariculture, Gondol, Bali \\ *) James Cook University (JCU) Australia
}

(Received 2 February 2011 ; Accepted 18 May 2011 1)

\begin{abstract}
The wide exploration of interferon (IFN)s in vertebrates for medical purposes has attracted researchers to investigate the existence of a similar role of interferon in other organisms such as invertebrates, including insects, and crustacea. A review of the literature indicates that there is no evidence of interferon existing either in insects such as $D$. melanogaster and $A$. gambiae which have had their genomes fully sequenced or in crustacea. However, a nonspecific antiviral state in crustacean, such as $P$. monodon can be efficiently triggered by both dsRNA and siRNA. The evidence suggests that anonymous cytokines, similar to interferon and not identical to any vertebrate IFNs, related to antiviral protection, do exist in crustacea. However, how widely spread of interferon immune response inducer or interferon-like molecules in this group is an important issue that remains to be explored.
\end{abstract}

KEYWORDS: interferon, crustacea, tiger shrimp

\section{INTRODUCTION}

Cytokines and interleukins (ILs) are soluble mediators that regulate the effectors' phase of immune responses (Ottoviani et al., 1995). One multigene family of the cytokines, interferon (IFNs) was identified in the late 1950s as the vertebrates' major innate antiviral response against several viral infections (Samuel, 2001). Interferon work by inducing viral and tumour resistance, modulate the effect of the immunesystem, and regulate the differentiation of cells (Gutterman, 1994; Guidotti \& Chisari, 2001; Pang et al., 2005). This finding precipitated several studies to explore the antiviral function of interferon. In fact, the use of IFNs for medical purposes, particularly for humans has developed since 1970s when interferon was successfully analysed and characterised, leading to the successful production of type I (IFN- $\alpha$ and IFN- $\beta$ ) for chemical, biological, and immunological studies (Pestka, 2007). Soon after this success, several assays such as polymerase chain reaction (PCR) and enzyme-linked immunosorbent assay (ELISA) and their kits have been widely developed to measure interferon (Fairchild \& Moorhead, 1985; Le Moal et al., 1989; Paasch et al., 1996; Siebert \& Larrick, 1992; Lessard et al., 1998).

The Food and Drug Administration (FDA), USA has approved both interferon type I and type II to be used for medical therapies. For instance, IFN- $\alpha$ is accepted for treatment of viral hepatitis, IFN- $\beta$ is permitted in sclerosis therapy, and IFN- $\gamma$ is approved in the chronic hereditary immune disorder, chronic granumalotous disease (Samuel, 2001). The approval paved the way for the commercial production of the drugs. In fact, the worldwide annual sales of the prescribed IFN-cytokine products recently valued well over US\$1 billion

\# Corresponding author. Research Institute for Mariculture, Jl. Br. Gondol, Kec. Gerokgak, Kab. Buleleng, Kotak Pos 140, Singaraja, Bali 81101 , Indonesia. Tel.: +62 36292278

E-mail address: dewi_rimg@yahoo.com 
(Kunzi \& Pitha, 2005). Considering the important role of IFNs for therapeutics and their values, it is therefore highly significant to discover the functions of the IFN-stimulatory gene products in the hope of categorizing extra pathways that will facilitate our understanding of the important biological events influenced by IFNs or IFN-like molecules in various organisms.

This literature review will describe the works of interferon or interferon-like molecules in both mammal and non-mammal vertebrates, including humans and bony fish and in invertebrates, including insects and crustacea based on past literatures. Understanding how these fundamental processes work in anti-viral immunity may facilitate how to manage pathogens of both species. In addition, the knowledge of interferon provides a great hope for addressing disease problems in crustacean culture.

\section{VERTEBRATES' INTERFERON RESPONSES AGAINST VIRAL INFECTION}

\section{In Humans}

The study of human (Homo sapiens) immunity demonstrated that in response to viruses, cytokine signals regulation of cell growth and development of hematopoietic tissues are triggered by interferon regulatory factors (IRFs) (Paun \& Pitha, 2007). These regulators play important roles within infected cells, facilitating viral, bacterial, and interferon-induced signalling pathways (Samuel, 2001). Previous studies confirmed that there are virus encoded analogous of cellular IRF and nine recognised human IRF genes, including IRF-1, IRF-2, IRF-3, IRF-4, IRF-5, IRF-6, IRF-7, IRF-8, and recently, IRF-9 (Nguyen et al., 1997; Barnes et al., 2002). The understanding of the molecular mechanism of the pathogen induced innate antiviral response was significantly enhanced by the identification of two IRF, namely, IRF-3, and IRF7 and their role in the transcriptional activation of type I IFN genes (Ronco et al., 1998; Au et al., 1998; Marie et al., 1998).

The fast production of interferon is the basis of the innate antiviral responses (Erickson $\&$ Gale, 2008). For these purposes, the activation of IRF-3 and IRF-7 which is crucial to the expression of IFN is suggested to be stimulated by distinct cellular receptors and signalling pathways (Akira et al., 2006; Honda et al.,
2005). These two IRFs are triggered as downstream effectors of pathogen recognition receptor (PRR) signalling cascades (Erickson \& Gale, 2008). PRRs are cellular proteins of the RNA-helicase family such as retinoic acid inducible gene-I (RIG-I), melanoma differentiation-associated protein-5 (MDA5), and the family of Toll-like receptors (TLRs) that employ particular viral products and signal to the nucleus to activate the expression of interferon-messenger RNA (IFN-mRNA) (Saito \& Gale, 2006).

IRF-3, which is constitutively present in the majority of cells provokes a preliminary signal for the expression of IFN from the infected cells that is enlarged upon successive activation and expression of IRF-7, which is also an interferon-stimulated gene (ISG) (Tamura et al., 2007). It is important to note that the expression of interferon by the main interferon producers, plasma cystoids dendritic cells (pDCs) is mainly determined by IRF-7 as the key transcription factor (Honda et al., 2005). It is totally responsible for the induction of IFN antiviral defences (Honda et al., 2005). The character of IRF-7 as an ISG demonstrates an essential predicament in immunity in which high intensity of IFN production and antiviral defences depends on the rate-limiting transcription of nuclear signalling of IRF-7 mRNA and ensuring the production of protein (Erickson \& Gale, 2008).

The synthesis of interferon is triggered by the induction of a cell corresponding to either IFN- $\alpha$ and $-\beta$ (viral infection) or IFN- $\gamma$ (antigen or mitogen stimulation). The replication of the virus is blocked in the IFN-treated cell in which synthesis of IFN-regulated proteins is induced by the action of paracrine-IFN (Figure 1).

Studies using biochemical, genetic, and cellbased approaches indicated that the cellular repressor proteins of translation initiation, eukaryotic translation initiation factor-4E (eiF4E)-binding proteins (4E-BPs), namely $4 \mathrm{E}-$ BP1 and 4E-BP2 played a key role in the synthesis of protein by stimulating mRNA translation as well as acting in the control of cell proliferation (Lawrence \& Abraham, 1997). $4 \mathrm{E}-\mathrm{BPs}$ are also key players in regulating the production of type-I IFN through translational contr-ol of IRF-7 expression (Figure 2A) that confers rapid protein production from preexisting but conversional silent mRNA pools (Colina et al., 2008). 


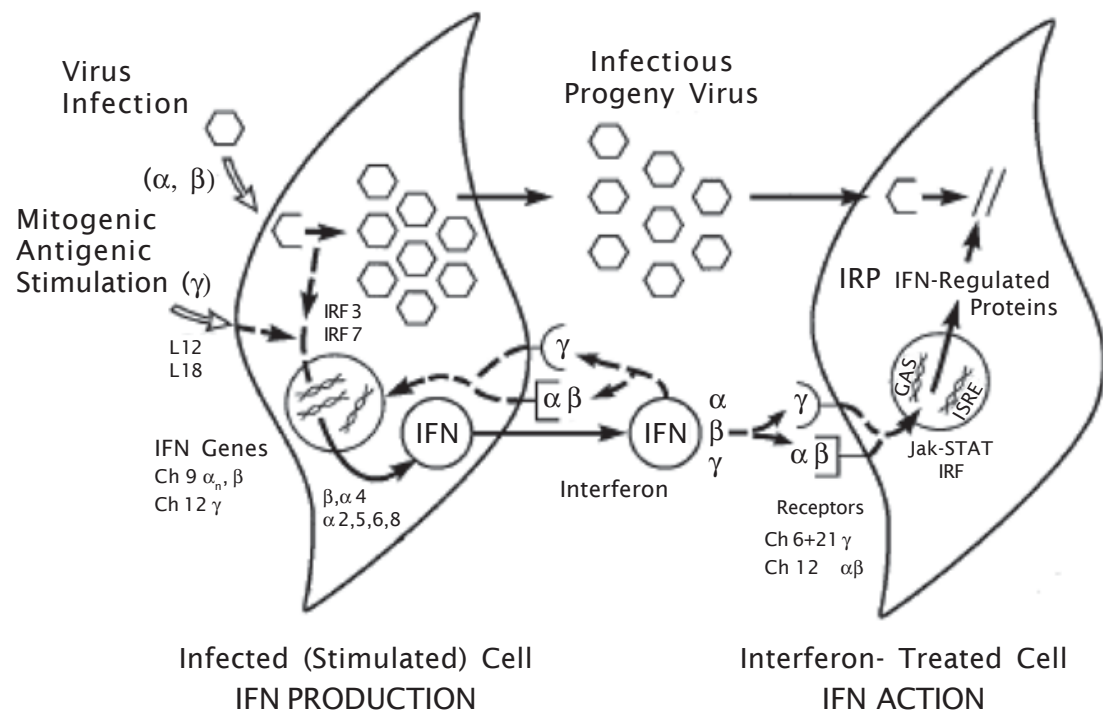

Figure 1. Production (left) and action (right) of IFN (modified from Samuel, 2001)

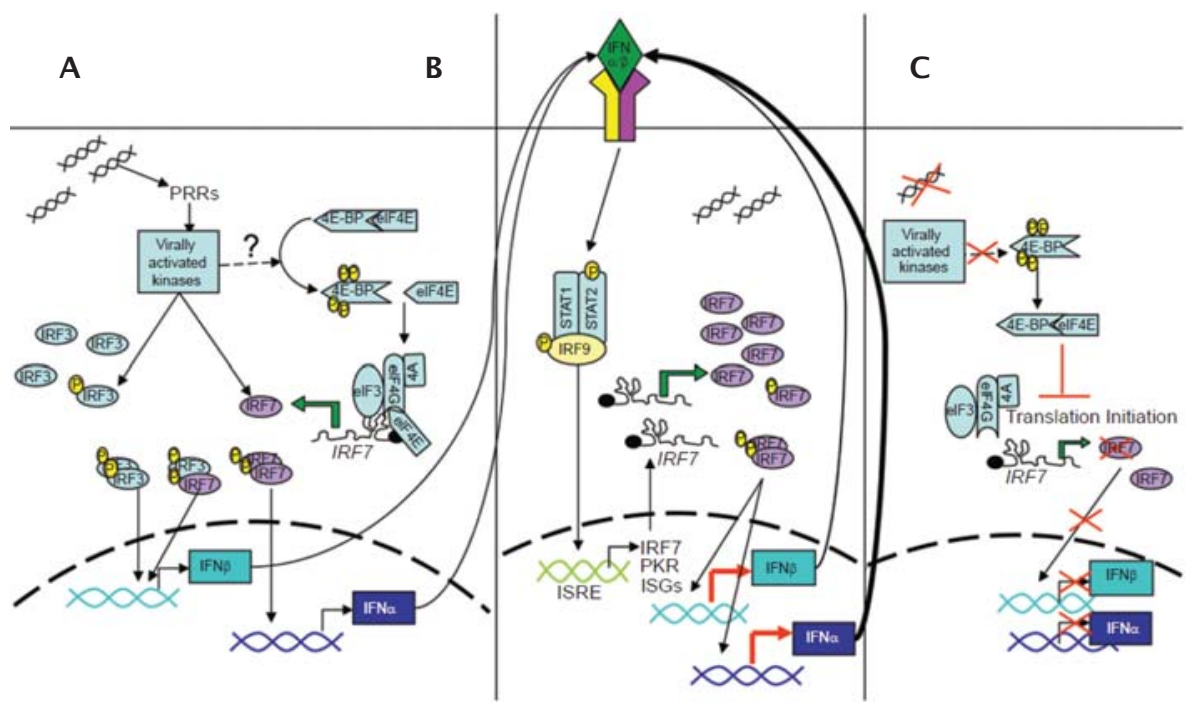

Figure 2. Steps in the response of interferon through 4E-BP translational suppression of IRF7. A. Activation of distinct signalling cascades; B. Activation of JAK/STAT pathway; C. Turning off the innate immune response by decreasing the production of interferon (fully explanation can be viewed in Erickson \& Gale, 2001)

The interferon response begins upon virus infection, allowing PRRs to bind to their respective viral ligands, resulting in the activation of distinct signalling cascades. The mammalian target of rapamycin (mTOR) or an undefined protein kinase may lead to hyperphosphorylation of $4 \mathrm{E}-\mathrm{BP}$, allowing release of the elF4E, which is now free to bind to elF4G, forming the eIF4F translation initiation complex (Figure 2A). This increase in the pool of functional elF4F allows the translation of mRNAs, such as IRF-7 mRNA, that were only 
inefficiently translated or translationally silent under conditions of 4E-BP hypophosphorylation. PRR signalling triggers the phosphorylation of IRF-7 and IRF-3 by virus-activated kinases to induce their activation and translocation to the nucleus, resulting in transcriptional activation of type I IFN genes. In the next stage, the secreted IFNs bind to their cognate receptor, interferon associated receptor-1/-2 (IFNAR 1/ 2 ), activating the Janus kinase (JAK) signal transducer and activator of transcription (STAT), the JAK/STAT pathway wherein the transcription factor, Interferon stimulated gene factor-3 (ISGF-3) which induces the expression of ISGs including IRF-7, RIG-I and RNAdependent protein kinase (PKR), and many others (Figure 2B). ISG products limit viral infection and enhance host immunity. After the viral clearance from the cells, it is imperative that the IFN response be dampened before it is harmful to the host. This may occur in part through translational-suppressive actions of the 4E-BPs on IRF-7 mRNA translation, which in turn decreases IFN production and turns off the innate immune response (Figure $2 \mathrm{C}$ ).

\section{Interferon in Bony Fish (Teleosts)}

A study on innate immunity of fish demonstrated that TLRs recognise the pathogenassociated molecular patterns (PAMPs) of microorganisms that can trigger the expression of inflammatory cytokines and genes with antimicrobial activity through the activation of nuclear factor kappa B (NFKB) (Ewart \& Tsoi, 2004). So far, a number of TLR genes and copy-DNA (cDNA)s have been identified in several fishes. Interestingly, the genome sequence of the pufferfish revealed clear similarity (orthologs) of mammalian TLR 2, 3, 4, $5,7,8$, and 9 , a proof that the genes have evolved from a common ancestor. In fact, the fish genome also encoded a TLR with an equally high sequence identity to mammalian $T L R 1,6$, and 10 . In general, the Toll signalling pathway runs through several phases (Figure 3 ). Initially, the exogenous ligands stimulate TLR to recruit two adaptor molecules, myeloid differentiation88 (MyD88) and tumor necrosis factor (TNF) receptor associated family-6 (TRAF6). As a consequence, two kinases, namely mitogenactivated protein (MAP) kinase or threonineactivated kinase (TAK-1) and Ikkinase (IKK) are activated through subsequent phosphorylation. The next stage, in example, the inactivation of $I \kappa B$ by phosphorylation, releasing the nuclear transcriptional factor kappa-B (NFkB) into the nucleus by which the transcription of immune and inflammatory genes is activated (Ewart \& Tsoi, 2004).

Several homologs of interferon in several bony fish has been cloned and characterised over the last decade. For instance, in zebra fish (Danio rerio) (Igawa et al., 2006); Japanese pufferfish (Tetraodon nigroviridis) (Zou et al., 2004), trout (Oncorhynchus mykiss) (Zou et al., 2005), Atlantic salmon (Salmo salar) (Robertson et al., 2007), catfish (Clarias gariepenus) (Milev-Milovanovic et al., 2006), common carp (Cyprinus carprio, L.) (Stolte et al., 2008) and goldfish (Carassius auratus) (Grayfer \& Belosevic, 2009). Two isoforms of IFN- $\gamma$, which differ markedly within each species in sequence homology and expression patterns apparently exist in zebrafish (D. rario), catfish (C. gariepenus), carp (C. carprio, L), and goldfish (C. auratus) (Igawa et al., 2006; MilevMilovanovic et al., 2006; Stolte et al., 2008). Various IFN and IFN-like activities in fish have been recently identified (Table 1.)

Interferon stimulatory genes (ISGs) were identified in rainbow trout (O. mykiss), namely MXI and Vig-2 whereas ISG15 was identified in goldfish (C. auratus) and Atlantic cod (Gadus morhua) (Collet \& Secombes, 2001; Boudinot et al., 2001; Liu et al., 2002; Seppola et al.,

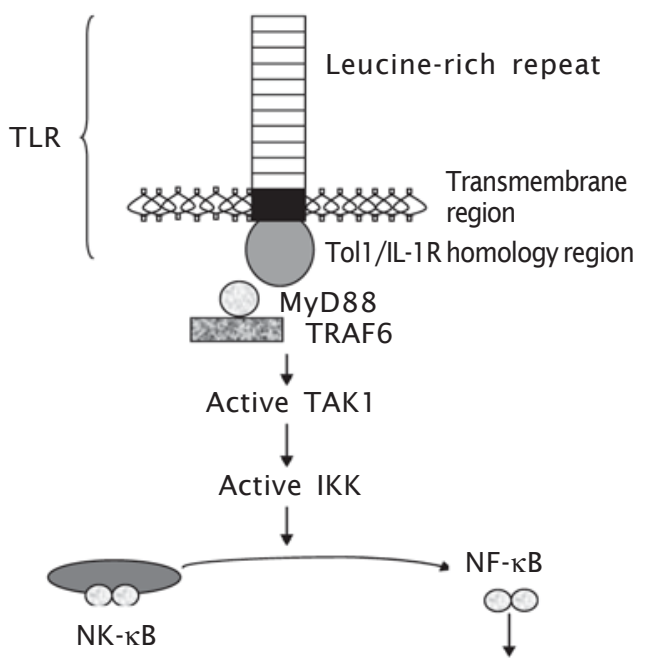

Nucleus translocation and transcription

Figure 3. Toll-signalling pathways in teleosts (Ewart \& Tsoi, 2004) 
Table 1. IFN and IFN-like activities identified in fish (adopted from Schultz et al., 2008)

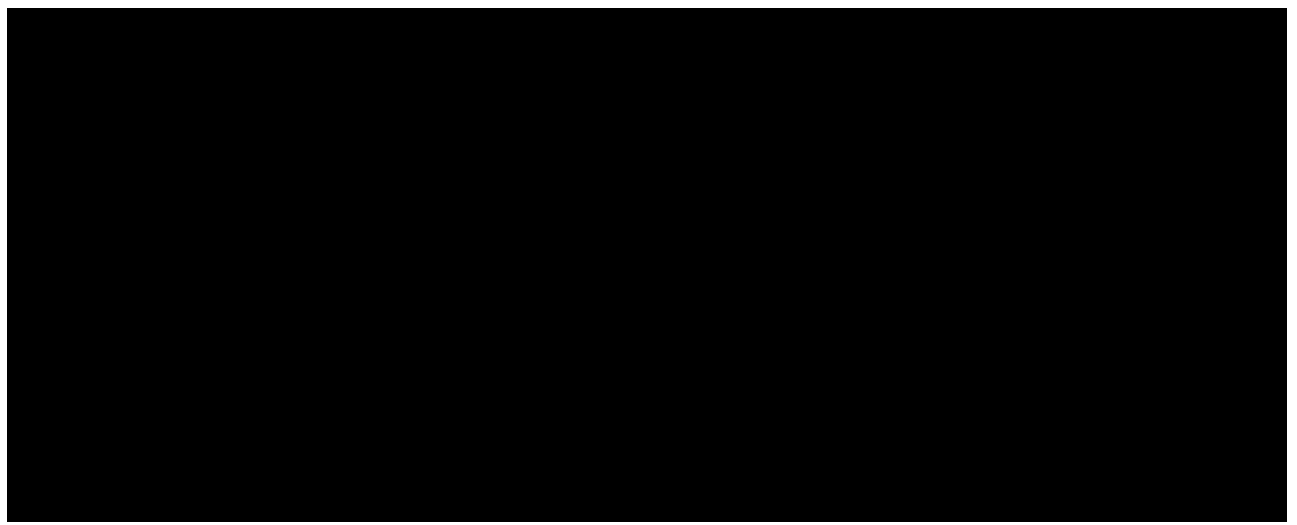

(MAF: Macrophage Activating Factor)

2006). Among the IRFs present in teleosts, IRF1 has been genetically copied and differentiated from the Japanese flounder (Paralichthys olivaceus), pufferfish (T. nigroviridis), rainbow trout (O. mykiss), turbot (Scophthamus maximus), and sea bream (Sparus aurata) (Yabu et al., 1998; Richardson et al., 2001; Collet et al., 2003a,b; Ord 'as et al., 2006). IRF2 has been described in rainbow trout $(O$. mykiss) and mandarin fish (Siniperca chuatsi), and is homologous to the recognized vertebrate IRF-2 (Collet et al., 2003a, b; Sun et al., 2006). In addition, IRF-7 has been cloned from goldfish (C. auratus) and mandarin fish (S. chuatsi) (Zhang et al., 2003; Sun et al., 2007). These studies also demonstrated that the IRFs identified in fish possess substantial attributes of mammalian IRFs.

There are three major factors, including virus, interferon, and a synthetic double stranded RNA which is a polyinosinic: polycytidylic acid (poly I:C) are experimentally used to trigger IRF genes in fish (Collet et al., 2003, Zhang et al., 2003; Ord 'as et al., 2006; Sun et al., 2006; 2007). For instance, IRF-1 in flounder ( $P$. olivaceus) was triggered by poly I:C (Collet et al., 2003a, b; Ord 'as et al., 2006). IRF-2 was triggered by poly I:C in trout $(O$. mykiss), and mandarin fish (S. chuatsi) (Collet et al., 2003a, b; Sun et al., 2006). Another gene, IRF-7 was up-regulated by virus-infection or treatment-based IFN in goldfish (C. auratus), and induced by poly I:C in mandarin fish $(S$. chuatsi) (Zhang et al., 2003; Sun et al., 2007).

The induction of poly I:C in snakehead (Channa argus) raises the expression of a cDNA encoding Carassius auratus IRF genes (Ca-IRF)s in the spleen and liver (Jia \& Guo, 2008). It was confirmed by real time PCR (RT-PCR) analyses that CaIRF- 1 and CalRF-2 genes for IRF- 1 in flounder ( $P$. olivaceous), pufferfish ( $T$. nigroviridis), trout (O. mykiss), turbot (S. maximus), and sea bream (S. aurata) (Yabu et al., 1998; Richardson et al., 2001; Collet et al., 2003a, b; Ord' as et al., 2006) and for IRF-2 in trout (O. mykiss), and mandarin fish ( $S$. chuatsi) (Collet et al., 2003a, b; Sun et al., 2006) were constitutive expression in a wide range of living-isolated tissues. However, CalRF-7 is primarily in the intestine, gill and peripheral blood, and varies from goldfish (C. auratus) IRF7 gene in a number of tissues (Zhang et al., 2003). Remarkably, significant levels of expression of three CalRF genes were highly identified in the intestine and gill (Zang et al., 2003). This possibly an indication of the reality that they are the entrance organs through which antigens including microbes invade the fish body, and where the immune response of the fish is instigated (Jia \& Guo, 2008). To date, a number of vertebrate IRFs genes and their protein sequences are available in GenBank (Table 2).

\section{INVERTEBRATES' IMMUNE RESPONSES AGAINST PATHOGENS}

On the contrary with vertebrates, there is still a lack of information at cellular or molecular level regarding invertebrates' immune response against viral infection because there is an absence of genes homologous to IFNs or to the main effectors of the IFN responses 
Table 2. Various vertebrate IRF genes which are deposited in GenBank (Modified from Jia \& Guo, 2008)

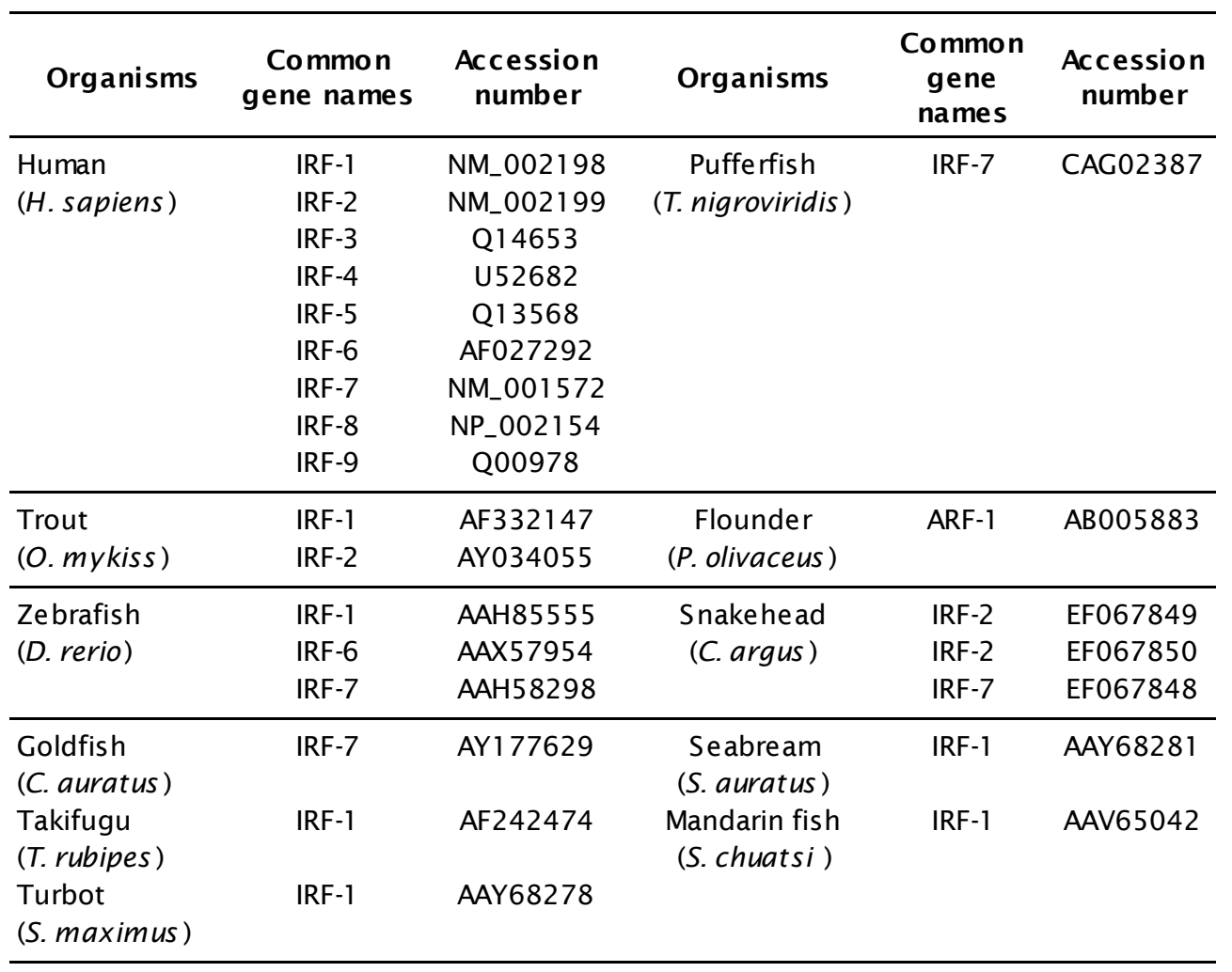

(Adams et al., 2000; Meurs et al., 1990). A more detailed approach to study the invertebrate immune system is required.

\section{In Insects}

Drosophila melanogaster has been widely used in the study of the invertebrate immune system as it has genetic malleability, a lack of a conventional mammalian adaptive immune system and the conservation of these signalling pathways with those of higher organisms. In addition Drosophila possesses a robust RNA interference (RNAi) system homologous to the post-transcriptional gene silencing (PTCS)/ RNAi systems similar to that in plants and other animals (Zambon et al., 2006).

As the genome of this fruit fly species has been completely sequenced (Adams et al., 2000), it has been widely accepted that invertebrates such as Drosophila lack of double-stranded RNA (dsRNA)-induced immune responses as a consequence of the absence of genes identical to IFNs or to the main effectors of the IFN such as RNA-dependent protein kinase (PKR) response (Robalino et al., 2004). However, the discovery of dsRNA-mediated posttranscriptional gene silencing or (PTCS) or RNA interference (RNAi) in Drosophila confirmed the complex properties of dsRNA in isolated living cells (Misquitta et al., 1999).

The discovery begins when an identical phenotype was observed with the removal of the nautilus gene product by genetic interference upon experimental injection of nautilus dsRNA (Misquitta et al., 1999). It also defined a crucial role for nautilus (nau) which is a single family member of Myogenic regulatory factor (MRFs) in Drosophila during embryonic muscle formation, providing a powerful approach of RNAi for the targeted disruption of a given genetic function in Drosophila (Misquitta et al., 1999).

In the further observation application of RNAi that was suggested correlated with an 
early antiviral mechanism involved in the limitation of viral gene product expression in infected cells as a result of the occurrence of viral dsRNAs during the course of infection as controls created phenotypes that are essentially indistinguishable from the original mutation (Misquitta et al., 1999).

Interestingly, the specific Janus kinase/ signal tranducer and activator of transcription (JAK/STAT) pathway and STAT-like molecules which are crucial in response to the stimulation of cytokine persist throughout animal evolution. Roughly, two STATs have been detected in the nematode, Caenorhabditis elegans (Liu et al., 1999), and three STAT-like molecules have been identified in the slime mould, Dictyostelium even though to date, no invertebrates have been identified to posse JAK-like protein kinases (Zeidler et al., 2000). What is more interesting to note in the immune systems of other invertebrates such as Drosophila melanogaster and Anopheles gambiae is that there is the evidence of the JAK/STAT as the signal transduction pathway identical to those well-known to control vertebrate IFN response (Zeidler et al., 2000; Christophides et al., 2002). In Drosophila, for example, the JAK/STAT pathway is not only involved in the control of haemopoiesis and sex differentiation, the segmentation of the embryo and the establishment of polarity within the adult compound eye but also partially worked in the expressed an immune role (Zeidler et al., 2000; Zambon et al., 2005). The identification of $242 \mathrm{~A}$. gambiae genes from 18 gene families implicated in innate immunity have demonstrated marked diversification virtual to that of Drosophila melanogaster (Christophides et al., 2002). The result confirmed that Anopheles has four Toll genes, namely Toll 6, 7, 8, and 9 that are clear orthologs of Drosophila counterparts. It also confirmed that other single genes such as My88, Tube, Pelle, and Cactus that were recognized in Anopheles were also ortholog with those in Drosophila and possess important role in the Toll signal transduction pathway (Christophides et al., 2002).

\section{Crustacean Immune Responses}

The complicated constraints in crustacean immune systems have led to several ineffective therapeutants such as immunostimulant and vaccines being used for rearing shrimps (Smith et al., 2003). These practices should be slowly phased out because it is believed they can trigger detrimental long term effects, including the risk of contamination to the environment and the final food product (Grant \& Briggs, 1998). They also contribute to the spread of drug resistant pathogens (Smith et al., 1994). Another constraint is a basic theory that the crustacea lack specific immunity such as that initiated in vertebrates and that they depend on pattern recognition protein (PRP) to counteract pathogens (Flegel, 2007). However, this theory should not exclude specific antiviral activities involved in crustacean which is until recently, still questionable. Several attempts have been made to figure out the role of antiviral responses in crustaceans.

It has been believed that microbial products such as lipopolysaccahrides or lipoglycans (LPS) and $\beta$-glucans as well as certain viral proteins can enhance viral resistance in shrimp (Song et al., 1997; Huang et al., 1999; Takahashi et al., 2000; Chang et al., 2003; Witteveldt et al., 2004). It is also has long been suggested that the sequence-independence induction of antiviral immunity by dsRNA merely exists in vertebrates. This might be true, however, there is ample evidence on the degradation of endogenous RNA as the result of sequence specific effects of dsRNA in many invertebrates (Robalino et al., 2004). For instance, Robalino et al. (2004) and He et al. (2005) provided optimism through their experiments using commercially important shrimp, Litopenaeus vannamei and Penaeus japonicus, respectively. In fact, under experimental conditions, the marine shrimp, L. vannamei surprisingly activated the innate antiviral response, similar to that of vertebrates' by recognising dsRNA as a virus-associated molecular pattern (Robalino et al., 2004). Three modes of crustacean antiviral immunity that actively battled two different major shrimp viruses, the Taura Syndrome Virus (TSV) and the White Spot Syndrome Virus (WSSV) were explored through the injection of dsRNA which significantly induced shrimp resistance, similar to that is conferred by mammal IFN type I (Robalino et al., 2004). The induction of this antiviral state was dsRNA-sequence independent and was therefore discrete from the sequence-specific dsRNA-mediated interference phenomenon (RNAi), providing the first evidence of the occurrence of an inducible nonspecific antiviral state in crustacea, indicating that interferon-like proteins, similar to that of vertebrates, could exist in shrimps. 
It has been suggested that there was a similarity of $40 \%$ between the unique clone of interferon like protein (IntIP) from experimentally WSSV-infected $P$. japonicus and IFN- $\alpha$ of sheep, mouse, and monkey by using a combination of suppression subtractive hybridization (SSH) and differential hybridization that was also used to profile gene expression of WSSV-resistant shrimp of $P$. japonicus (He et al., 2005). However, the interpretation of these results requires careful scrutiny. First, it does not explain the IntIP antiviral activity and its expression in WSSV-resistant shrimps and did not confirm the IntIP (one clone) in the haemocytes of naive shrimps of $P$. japonicus (Rossa \& Barracco, 2008). Secondly, the deposited sequences in GenBank completely differed to any interferon or IFN conserved domains and to any other known protein because the deposited 5' 3 'open reading frame (ORF) of their presumed IntIP from $P$. japonicus without a larger sequence containing 5' and 3' adjacent regions. In addition,the alignment between $P$. japonicus IntIP and mammalian interferon was poorly described. For instance, the analysis of IntIP sequence in GenBank database by using Basic Local Alignment Search Tool-x (BLASTx) program resulted in a translated nucleotide sequence (5'3' frame 3) strongly matched (60\%-73\% identity) with mitochondrial olygomycin binding fraction- adenosine triphosphate synthase-beta chain ( $\mathrm{F}_{0}$-ATP synthase$\beta$ chain) of insects (Rosa \& Barracco, 2008). There was also no expression of IntIP in the haemocytes the naive $P$. japonicus (Rosa \& Barracco, 2008).

The recombinant IntlP was suggested to have significant power to decrease the cytopathic effect (CPE) caused by Singapore grouper iridovirus (SGIV) on grouper embryonated egg (GP) cells $\left(\mathrm{EC}_{50}=10 \mu \mathrm{g} / \mathrm{mL}\right.$ ) and was not cytotoxic to the fish cells $\mathrm{CC}_{50}>200 \mu \mathrm{g} / \mathrm{mL}$ (He et al., 2005). Although this may in fact occur, the reason why antiviral activity of IntIP and its' expression only in WSSV-resistant $P$. japonicus is still not understood even though the expression of the recombinant, the antiviral activity of $P$. japonicus IntIP on SGIV-GP cell lines was examined (Rosa \& Barracco, 2008). Finally, the differential expression of a four clones 2'5'- oligoadenylate synthetase (OAS), in the WSSV-infected $P$. japonicus which was claimed has $32 \%$ identity with that of mouseOAS was unconfirmed because the sequences were neither reported nor deposited in the
GenBank. Therefore, it is probable that interferon like molecule of $P$. japonicus highly corresponds to a partial sequence of mitochondrial $F_{0}$-ATP synthase $\beta$ chain, constitutively expressed, and not to an induced-IFN (Rosa \& Barracco, 2008).

\section{CONCLUSION}

The existence of interferon in vertebrates is definite. On the other hand, the role of IFN in invertebrates is still unknown. The evidence indicates that invertebrates such as insects and crustacean possess interferon-like molecules as their immune systems specifically deal with pathogen invaders. However, how widely spread of interferon immune response inducer or interferon-like molecules in these groups of animals is an important issue that remains to be explored.

Apart from the ambiguity in the findings of He et al. (2005), to date, no other successful identification of the homolog-IFN in crustacea such as shrimps, has been made Indeed, the fact that gene sequences homolog to vertebrate interferon were absent in the available complete genomes of protostomes, including the animal class of insects and crustaceans also supports the idea of a lack of interferon or IFN-like molecules in shrimp (Rosa \& Barracco, 2008).

Thus, it is crucial to stress that a nonspecific antiviral state in shrimps can be efficiently triggered by both dsRNA and siRNA, leading to a rational consideration that anonymous cytokines, with no apparent identity to vertebrate IFNs are present in shrimps and are responsible for antiviral protection. In addition to this, the recent finding of identical vertebrate interferon response through Janus kinase (JAK)like molecules and signal tranducer as well as activator of transcription (STAT)-like molecules in insects sheds new light to the invertebrate immune system. Optimistically, these immune proteins can be identified in a near future and after exposing the molecular sources of their induction and routes, they could spawn a better approach in to the management of shrimp viral diseases in the aquaculture systems (Rosa \& Barracco, 2008).

\section{REFERENCES}

Adams, M.D., Celniker, S.E., Holt, R.A., et al. (173 co-authors). 2000. The genome sequence of Drosophila melanogaster. Science, 287: 2,185-2,189. 
Akira, S., Uematsu, S., \& Takeuchi, O. 2006. Pathogen recognition and innate immunity. Cell., 124: 783-801.

Altmann, S.M., Mellon, M.T., Distel, D.L., \& Kim, C.H. 2003. Molecular and functional analysis of an interferon gene from the zebrafish Danio rerio. J. Virol., 77: 1,992-2,002.

Au, W.C., Moore, P.A., LaFleur, D.W., Tombal, B., \& Pitha, P.M. 1998. Characterization of the interferon regulatory factor- 7 and its potential role in the transcription activation of interferon A genes. J. Biol.Chem., 44: 29,210-29,217.

Barnes, B., Lubyova, B., \& Pitha, P.M. 2002. On the role of IRF in host defense. J Interferon Cytokine Res., 22: 59-71.

Boudinot, P., Salhi, S., Blanco, M., \& Benmansour, A. 2001. Viral haemorrhagic septicaemia virus induces vig-2 a new interferonresponsive gene in rainbow trout. Fish Shellfish Immunol., 11: 383-397.

Chang, C.F., Su, M.S., Chen, H.Y., \& Liao, I.C. 2003. Dietary $\beta$-1,3-glucan effectively improves immunity and survival of Penaeus monodon challenged with white spot syndrome virus. Fish Shellfish Immunol., 15: 297-310.

Christophides, G.K., Zdobnov, E., Barillas-Mury, C., et al. (33 co-authors). 2002. Immunityrelated genes and gene families in Anopheles gambiae. Science, 298: 156-165.

Colina, R., Costa-Mattioli, M., Dowling, R.J., Jaramillo, M., Tai, L.H., Breitbach, C.J., Martineau, Y., Larsson, O., Rong, L., Svitkin, Y.V., Makrigiannis, A.P., Bell, J.C., \& Sonenberg, N. 2008. Translational control of the innate immune response through IRF7. Nature, 452: 323-328.

Collet, B., McDonald, C., \& Secombes, C.J. 2003a. The promoter for the interferon regulatory factor (IRF)-2 in the rainbow trout Oncorhynchus mykiss: cloning and reporter gene activity. Fish Shellfish Immunol., 5: 473-477.

Collet,B., Hovens, G.C.J, Mazzoni,D., Hirono, I., Aoki, T., \& Secombes, C.J. 2003b. Cloning and expression analysis of rainbow trout Oncorhynchus mykiss interferon regulatory factor-1 and -2 (IRF-1 and IRF-2). Dev Comp Immunol., 27: 111-126.

Collet, B. \& Secombes, C.J. 2001 . The rainbow trout (Oncorhynchus mykiss) Mxl promoter: structural and functional characterization. Eur. J. Biochem., 268: 1,577-1,584.
Collet, B., \& Secombes, C.J. 2002. Type I-interferon signalling in fish. Fish Shellfish Immunol., 12: 389-397.

Congleton, J. \& Sun, B.L. 1996. Interferon-like activity produced by anterior kidney leucocytes of rainbow trout stimulated in vitro by infectious hematopoietic virus or poly I:C. Dis. Aquatic Org., 25: 185-195.

de Kinkelin, P. \& Dorson, M. 1973. Interferon production in rainbow trout (Salmo gairdneri) experimentally infected with Egtved. virus. J. Gen. Virol., 19: 125-127.

Erickson, A.K. \& Gale, M.Jr. 2008. Regulation of interferon production and innate antiviral immunity through translational control of IRF-7. Cell Research., 18: 433-435.

Ewart, K.V. \& Tsoi, S.C.M. 2004. Innate immune recognition of pathogens in teleosts fish. in: Yin, L.A. (ed.). Current trends in the study of bacterial and viral fish and shrimp diseases, Molecular Aspects of Fish and Marine Biology, 3: 82-116.

Fairchild, R.L. \& Moorhead, J.W. 1985. A simple and sensitive ELISA to detect Immune $\gamma$ interferon induced I-A on a macrophage line. J. of Immunological Methods, 85: 183193.

Flegel, T.W. 2007. Update on viral accommodation: a model for host-viral interaction in shrimp and other arthropods. Developmental and Comparative Immunology, $31: 217$ 223.

Francis, C.H. \& Ellis, A.E. 1994. Production of lymphokine (macrophage activating factor) by salmon (Salmo salar) leucocytes stimulated with outer membrane protein antigens of Aeromonas salmonicida. Fish Shellfish Immunol., 4: 489-497.

Graham, S. \& Secombes, C.J. 1990. Do fish lymphocytes secrete interferon- $\gamma$ ?. J. Fish Biol. 36: 563-573.

Grant, A. \& Briggs, A.D. 1998. Use of ivermectin in marine fish farms: some concerns. Mar Pollut Bull. 36: 566-568.

Grayfer, L. \& Belosovic, M. 2009. Molecular characterization expression and functional analysis of goldfish (Carassius auratus L.) interferon gamma. Developmental and Comparative Immunology, 33: 235246.

Guidotti, L.G. \& Chisari, F.V. 2001 . Noncytolytic control of viral infections by the innate and adaptive immune response. Annu. Rev. Immunol., 19: 65-91. 
Gutterman, J.U. 1994. Cytokine therapeutics: Lessons from interferon- $\alpha$. Proc. Nadl. Acad. Sci. USA, 91: 1,198-1,205.

He, N., Qin, Q., \& Xua, X. 2005. Differential profile of genes expressed in hemocytes of White Spot Syndrome Virus-resistant shrimp (Penaeus japonicus) by combining suppression subtractive hybridization and differential hybridization. Antiviral Research, 66: 39-45.

Honda, K., Yanai, H., Negishi, H., Asagiri, M., Sato, M., Mizutani, T., Shimada, N., Ohba, Y., Takaoka, A., Yoshida, A., \& Taniguchi, T. 2005. IRF-7 is the master regulator of typeI interferon-dependent immune responses. Nature, 434: 772-777.

Huang, C.C. \& Song, Y.L. 1999. Maternal transmission of immunity to white spot syndrome associated virus (WSSV) in shrimp (Penaeus monodon). Dev. Comp. Immunol., 23: 545-552.

Igawa, D., Sakai, M., \& Savan, R. 2006. An unexpected discovery of two interferon gamma-like genes along with interleukin (IL)-22 and -26 from teleost: IL-22 and -26 genes have been described for the first time outside mammals. Mol. Immunol., 43: 999-1,009.

Jia, W. \& Guo, Q. 2008. Gene structures and promoter characteristics of interferon regulatory factor 1 (IRF-1), IRF-2, and IRF-7 from snakehead Channa argus. Molecular Immunology, 45: 2,419-2,428.

Kunzi, M.S. \& Pitha, P.M. 2005. Interferon Research: A Brief History. in: Carr JJ (ed.). Interferon methods and protocols. Humana Press, p. 25-35.

Lawrence, Jr, J.C. \& Abraham, R.T. 1997 PHAS/ $4 \mathrm{E}-\mathrm{BPs}$ as regulators of mRNA translation and cell proliferation. Trends Biochem. Sci., 22: 345-349.

Le Moal, M.A., Motta, I., \& Truffa-Baehi, P. 1989. Improvement of an ELISA bioassay for the routine titration of murine interferongamma. Res Immunol. 140: 613-624.

Lessard, M., He, S., \& Benkel, B. 1998. A quantitative competitive reverse transcription polymerase chain reaction technique to measure porcine interferon-gamma. J. Anim Sci., 76: 2,155-2,161.

Levy, D.E. \& Garcia-Sastre, A. 2001. The virus battles: IFN induction of the antiviral state and mechanisms of viral evasion. Cytokine Growth Factor Rev., 12: 143-156.
Liu, L.X., Spoerke, J.M, Mulligan, E.L. et al. (12 co-authors). 1999. High-throughput isolation of Caenorhabditis elegans deletion mutants. Genome Res., 9: 859-867.

Liu, M., Reimschuessel, R. \& Hassel, B.A. 2002. Molecular cloning of the fish interferon stimulated gene $15 \mathrm{kDa}$ (ISG15) orthologue: a ubiquitin-like gene induced by nephrotoxic damage. Gene, 298: 129-139.

Marie, I., Durbin, J.E., \& Levy, D.E. 1998. Differential viral induction of distinct interferonalpha genes by positive feedback through interferon regulatory factor-7. Embo J., 17: 6,660-6,669.

Meurs, E., Chong, K., Galabru, J., Thomas, N.S., Kerr, I.M., Williams, B.R., \& Hovanessian, A.G. 1990. Molecular cloning and characterization of the human double-stranded RNAactivated protein kinase induced by interferon. Cell. 62:379-390.

Milev-Milovanovic, I., Long, S., Wilson, M., Bengten, E., Miller, N.W., \& Chinchar, V.G. 2006. Identification and expression analysis of interferon gamma genes in channel catfish. Immunogenetics, 58: 70-80.

Misquitta, L. \& Paterson, B.M. 1999. Targeted disruption of gene function in Drosophila by RNA interference (RNA-i): A role for nautilus in embryonic somatic muscle formation. Proc. Natl. Acad. Sci., USA, 96: 1,4511,456 .

Mulero, V. \& Meseguer, J. 1998. Functional characterization of macrophage-activating factor produced by leucocytes of gilthead seabream (Sparus aurata L.). Fish \& Shellfish Immunol., 8: 143-156.

Nguyen, H., Hiscott, J., \& Pitha, P.M. 1997. The growing family of interferon regulatory factors. Cytokine Growth Factor Rev., 8: 293312.

Ord'as, M.C., Abollo, E., Costa, M.M., Figueras, A., \& Novoa, B. 2006. Molecular cloning and expression analysis of interferon regulatory factor-1 (IRF-1) of turbot and sea bream. Mol. Immunol. 43: 882-890.

Ottoviani, E., Franchini, A., Cassanehi, S., \& Genedani, S. 1995. Cytokines and invertebrate immune responses. Bio Cell. 85: 87-91.

Paasch, B.D., Reed, B.R., Keck, R., Sandlund, B.K., Gilkerson, E., \& Shalaby, R. 1996. An evaluation of the accuracy of four ELISA methods for measuring natural and recombinant human interferon-g. J. of Immunological Methods, 198: 165-176. 
Pang, K.R., Wu, J.J., Huang, D.B., Tyring, S.K., \& Baron, S. 2005. Biological and clinical basis for molecular studies of interferons. in: Carr, J.J. (ed.). Interferon methods and protocols. Humana Press, p. 1-23.

Paun. A. \& Pitha, P.M. 2007. The IRF family revisited. Biochimie, 89: 744-753.

Pestka, S. 2007. The interferons: 50 years after their discovery there is much more to learn. J. Biol Chem., 282: 20,047-20,051.

Richardson, M.P, Tay, B.H, Goh, B.Y, Venkatesh, B., \& Brenner, S. 2001 . Molecular cloning and genomic structure of a gene encoding interferon rregulatory factor. Mar. Biotechnol., 3: 145-151.

Robalino, J, Browdy, C.L., Prior, S., Metz, A., Parnell, P., Gross, P., \& Warr, G. 2004. Induction of antiviral immunity by doublestranded RNA in a marine invertebrate. J. Virol., 78: 10,442-10,448.

Robertson, M.J, Scruton, D.A., \& Clarke, K.D. 2007. Seasonal effects of suspended sediment on the behaviour of juvenile Atlantic salmon. Transactions of the American Fisheries Society, 136: 822-828.

Ronco, L.V., Karpova, A.Y., Vidal, M., \& Howley, P.M. 1998. Human papillomavirus 16 E6 oncoprotein binds to interferon regulatory factor- 3 and inhibits its transcriptional activity. Genes. Dev., 12: 2,061-2,072.

Rosa, R.D. \& Barracco, M.A. 2008. Shrimp interferon is rather a portion of the mitochondrial $\mathrm{F}_{0}$-ATP synthase than a true á-interferon. Molecular Immunology, 45: 3,490-3,493.

Saito, T. \& Gale, M.Jr. 2006. Principles of intracellular viral recognition. Curr. Opin. Immunol., 19: 17-23.

Samuel, C.E. 2001. Antiviral actions of interferons. Clin. Microbiol. Rev., 14: 778809.

Schultz, U., Kaspers, B., \& Staeheli, P. 2008. The interferon system of non-mammalian vertebrates. Developmental and Comparative Immunolog., 28: 499-508.

Seppola, M., Olsen, R.E., Sandaker, E., Kanapathippillai, P., Holzapfel, W., \& Ringø, E. 2006. Random amplification of polymorphic DNA (RAPD) typing of carnobacteria isolated from hindgut chamber and large intestine of Atlantic cod (Gadus morhua L.). Syst. Appl. Microbiol., 29: 131-137.

Siebert, P.D. \& Larrick, J.W. 1992. Competitive PCR. Product review. Nature, 359: 557-558.
Smith, P., Hiney, M.P., \& Samuelsen, O.B. 1994. Bacterial resistance to antimicrobial agents used in fish farming: a critical evaluation of method and meaning. Ann. Rev. Fish Dis. 4: 273-313.

Smith, V.J., Brown, J.H., \& Hauton, C. 2003. Immunostimulation in crustaceans: does it really protect against infection?. Fish \& Shellfish Immunology. 15: 71-90.

Song, Y.L., Liu, J.J, Chan, L.C., \& Sung, H.H. 1997. Glucan-induced disease resistance in tiger shrimp (Penaeus monodon). Dev. Biol. Stand., 90: 413-421.

Stolte, E.H., Nabuurs, S., Bury, N.R., Sturm, A., Gert Flik, G., Savelkoul, H.F.J., \& Lidy Verburg-van Kemenade. 2008. Stress and innate immunity in carp: Corticosteroid receptors and pro-inflammatory cytokines. Molecular Immunology, 46: 70-79.

Sun, B.J., Wang, G.L., Xie, H.X., Gao, Q., \& Nie, P. 2006. Gene structure of the mandarin fish (Siniperca chuatsi) goose-type lysozyme with its' expression in Escherichia coli. Aquaculture, 252: 106-113.

Sun, B.J., Chang, M.X., Song, Y., Yao, W.J., \& Nie, P. 2007. Gene structure and transcription of IRF- 1 and IRF-7 in the mandarin fish Siniperca chuatsi. Veterinary Immunology and Immunopathology, 1 16:26-36.

Tafalla, C. \& Novoa, B. 2000.Requirements for nitric oxide production by turbot (Scophthalmus maximus) head kidney macrophages. Dev. Comp. Immunol., 24: 623-631.

Takahashi, Y., Kondo, M., Itami, T., Honda, T., Inagawa, H., Nishizawa, T., Soma, G.I., \& Yokomizo, Y. 2000. Enhancement of disease resistance against penaeid acute viraemia and induction of virus-inactivating activity in haemolymph of kuruma shrimp, Penaeus japonicus, by oral administration of Pantoea agglomerans lipopolysaccharide (LPS). Fish Shellfish Immunol., 10: 555-558.

Tamura, T., Yanai, H., Savitsky, D., \& Taniguchi, T. 2007. The IRF Family Transcription Factors in Immunity and Oncogenesis. Annu. Rev. Immunol., 26: 535-84.

Westenberg, M., Heinhuis, B., Zuidema, D., \& Vlak, J.M. 2005. siRNA injection induces sequence-independent protection in Penaeus monodon against white spot syndrome virus. Virus Res., 114: 133-139.

Witteveldt, J, Cifuentes, C.C., Vlak, J.M., \& van Hulten, M.C. 2004. Protection of Penaeus 
monodon against white spot syndrome virus by oral vaccination. J. Virol., 78: 2,0572,061 .

Yabu, T., Hirose, H., Hirono, I., Katagiri, T., Aoki, T., \& Yamamoto, E. 1998. Molecular cloning of a novel interferon regulatory factor in Japanese flounder Paralichthys olivaceus. Mol. Mar. Biol. Biotechnol. 7: 138-144.

Yin, Z., Lam, T.H., \& Sin, Y.M. 1997. Cytokinemediated antimicrobial immune response of catfish Clarias gariepinus as a defence against Aeromonas hydrophila. Fish \& Shellfish Immunol., 7: 93-104.

Zambon, R.A., Nandakumar, M., Vakharia, V.N., \& $\mathrm{Wu}$, L.P. 2005. The Toll pathway is important for an antiviral response in Drosophila. Proc. Natl. Acad. Sci. USA, 102: 7,257-7,262.

Zambon, R.A., Vakharia, V.N., \& Wu, L.P. 2006. RNAi is an antiviral immune response against a dsRNA virus in Drosophila melanogaster. Cellular Microbiology, 8: 880-889.
Zeidler, M.P., Bach, E.A., \& Perrimon, M. 2000. The roles of the Drosophila JAK/STAT pathway. Oncogene, 19: 2,598-2,606.

Zhang, Y.B., Hu, C.Y., Zhang, J., Huang, G.P., Wei, L.H., Zhang, Q.Y.\& Gui, J.F. 2003. Molecular cloning and characterization of crucian carp (Carassius auratus L.) interferon regulatory factor 7 . Fish Shellfish Immunol., 15: 453-466.

Zou, J., Bird, S., Truckle, J., Bols, N., Horne, M., \& Secombes, C.J. 2004. Identification and expression analysis of an IL-1 8 homologue and its alternatively spliced form in rainbow trout (Oncorhynchus mykiss). Eur. J. Biochem., 271: 1,913-1,923.

Zou, J., Carrington, A., Collet, B., Dijkstra, J.M., Yoshiura, Y., Bols, N., \& Secombes, C.J. 2005. Identification and bioactivities of IFNã in rainbow trout Oncorhynchus mykiss: the first Th1-type cytokine characterized functionally in fish. J. Immunol., 175: 2,4842,494 . 